\title{
Impact of socio-economic status on hospital length of stay following injury: a multicenter cohort study
}

Lynne Moore ${ }^{1,2^{*}}$, Brahim Cisse ${ }^{1,2}$, Brice Lionel Batomen Kuimi ${ }^{1,2}$, Henry T. Stelfox ${ }^{3}$, Alexis F. Turgeon ${ }^{1,2,4}$, François Lauzier ${ }^{2,5}$, Julien Clément ${ }^{6}$ and Gilles Bourgeois ${ }^{7}$

\begin{abstract}
Background: Injury is second only to cardiovascular disease in terms of acute care costs in North America. One key to improving injury care efficiency is to generate knowledge on the determinants of resource use. Socio-economic status (SES) is a documented risk factor for injury severity and mortality but its impact on length of stay (LOS) for injury admissions is unknown. This study aimed to examine the relationship between SES and LOS following injury. This multicenter retrospective cohort study was based on adults discharged alive from any trauma center (2007-2012; 57 hospitals; 65,486 patients) in a Canadian integrated provincial trauma system. SES was determined using ecological indices of material and social deprivation. Mean differences in LOS adjusted for age, gender, comorbidities, and injury severity were generated using multivariate linear regression.

Results: Mean LOS was 13.5 days. Patients in the highest quintile of material/social deprivation had a mean LOS 0.5 days (95\% Cl 0.1-0.9)/1.4 days (1.1-1.8) longer than those in the lowest quintile. Patients in the highest quintiles of both social and material deprivation had a mean LOS 2.6 days (1.8-3.5) longer than those in the lowest quintiles.

Conclusions: Results suggest that patients admitted for traumatic injury who suffer from high social and/or material deprivation have longer acute care LOS in a universal-access health care system. The reasons behind observed differences need to be further explored but may indicate that discharge planning should take patient SES into consideration.
\end{abstract}

Keywords: Injury, Hospital length of stay, Socioeconomic status, Material deprivation, Social deprivation

\section{Background}

Each year, approximately 212,000 Canadians are hospitalized following injury, 68,000 are permanently impaired and 14,000 die with direct costs estimated at 20 \$ billion [1]. Trauma care is one of the most resourceintensive medical specialties and second only to cardiovascular diseases in terms of health care costs [1]. Unnecessary hospital days represent an estimated $20 \%$

\footnotetext{
* Correspondence: Lynne.moore@fmed.ulaval.ca

${ }^{1}$ Department of social and preventive medicine, Laval University, Quebec,

QC, Canada

${ }^{2}$ Population Health and Optimal Health Practices Research Unit,

Trauma - Emergency - Critical Care Medicine, Centre de Recherche du Centre Hospitalier Universitaire de Québec (CHU de Québec - Hôpital de

I'Enfant-Jésus), Laval University, Québec, QC, Canada

Full list of author information is available at the end of the article
}

of total length of stay (LOS) in acute care hospitals [2] implying an important waste of resources as well as increased patient exposure to adverse events and functional decline [3-5]. Reducing LOS has been identified as one of the core strategies for alleviating health care financial pressure and improving patient outcome [6]. Other than poor quality of care, many factors are now being considered as drivers of unnecessarily prolonged hospital stays, including socio-economic status (SES) [6].

The impact of SES on LOS related to general admissions [7] or specific diagnoses such as stroke [8], pneumonia [9, 10], and psychiatric conditions [11] has been widely discussed in the literature [12-15]. In addition, low SES has been consistently documented as a risk factor for injury-related mortality, injury hospitalizations, 
and injury severity [16]. However, compared to chronic disease populations, injury admissions represent younger patients with fewer comorbidities, different discharge patterns and specific socio-economic issues [17]. In order to improve the quality and efficiency of acute injury care, we need to improve our understanding of the influence of SES on LOS for injury admissions.

The objective of this study was to examine the relationship between SES and hospital LOS following an acute care admission for injury.

\section{Methods}

\section{Study Population}

This retrospective, multicenter cohort study was based on the integrated and mature trauma system in Québec, Canada, instated in 1993. The trauma system comprises a network of specialized acute care centers from level I (highly specialized urban centers with neurosurgical coverage 24/7) to level IV (small rural community hospitals). The system currently comprises 59 hospitals designated according to American College of Surgeons criteria including 5 level I (of which 2 are pediatric), 5 level II, 21 level III, and 28 level IV centers. All level I centers are trauma teaching hospitals.

The study population was identified using the provincial trauma registry and included all adults $(\geq 16$ years old) hospitalized between April 1, 2007 and February 28, 2012 with a principal diagnosis of injury (International Classification of Diseases, version 9 codes 800-859 excluding late effects and complications, foreign bodies, poisoning, drowning and burns) admitted to any of the trauma system's 57 adult trauma centers according to the following trauma registry inclusion criteria: length of stay $>3$ days, intensive care unit admission, or transfer from another hospital. In-hospital deaths as well as patients aged 65 years or older with isolated hip fractures and no other major injuries were excluded [18]. The latter are excluded because isolated hip fractures are widely considered to be the consequence of chronic disease [18] and these patients are often treated in hospitals outside the trauma system.

\section{Study data sources}

The trauma registry is maintained through an application housed in each trauma center and connected to a unique central database located at the Ministry of Health. Data collection is mandatory for all patients meeting the inclusion criteria described above. To ensure the reliability and validity of data in the registry, the Ministry of Health conducts regular audits to identify and correct aberrant data values in all data fields and to verify date and time chronology.

\section{Primary outcome}

The primary outcome was acute care LOS, calculated as the number of days between admission and discharge.

\section{Socio-economic status}

SES was quantified using ecological indices of social and material deprivation derived and validated previously using Canadian census data $[19,20]$ and based on the work by Townsend [21]. These indices are based on the smallest geostatistical unit used in the Canadian census (400 to 700 persons on average) and defined by patients' postal code $[1,20]$. Material deprivation encompasses education (proportion without a high school diploma), employment (the employment/population ratio), and income (average household income). Social deprivation is based on the proportion of people separated, divorced, or widowed; living alone; and single-parent families. The two composite indices were derived using principal components analysis, standardized for age and sex, and divided into quintiles [16]. Patients in the highest quintile are those suffering from the greatest material/social deprivation. This ecological approach is widely used as a proxy for individual SES data $[1,16,19,22]$ and the indices used in this study have been used to evaluate the influence of SES on health outcomes in several Canadian cohort studies [23-26]. We explored the effect of material and social deprivation individually and the interaction between the two. For the latter, patients in the highest quintile of material and social deprivation were compared to those in the lowest quintile for both indices [20].

\section{Statistical analysis}

We used a mixed linear model to estimate mean differences in hospital LOS across SES categories adjusted for physiological reserve, anatomical injury severity, physiological reaction to injury, and transfer status. Physiological reserve was described using age, gender and the number of comorbidities, according to Charlson's classification [27]. Anatomical injury severity was described by the mechanism of injury, body region of the most severe injury and the maximum Abbreviated Injury Scale score (AIS) [28]. The AIS is a lexicon describing anatomical injuries, each one accompanied by a severity grade from 1 (least severe) to 6 (most severe), established by expert consensus. Physiological response to injury was quantified using the Glasgow Coma Scale (GCS) score [29], a measure of state of consciousness from 3 (no reaction) to 15 (fully alert), systolic blood pressure (SBP) and respiratory rate (RR), all measured on arrival at the emergency department. Independent variables were modelled as dummy variables on categories, as specified in Table 1. A random intercept on hospital was used to control for clustering by trauma center. 
Table 1 Description of the study population according to the highest levels of material and social deprivation

\begin{tabular}{|c|c|c|c|c|}
\hline \multicolumn{2}{|c|}{ Characteristics of the study population $\mathrm{n}(\%)$} & \multirow{2}{*}{$\begin{array}{l}\text { Whole study population } \\
65,486\end{array}$} & \multirow{2}{*}{$\begin{array}{l}\text { Material deprivation Quintile } 5 \\
17,172(26.3)\end{array}$} & \multirow{2}{*}{$\begin{array}{l}\text { Social deprivation Quintile } 5 \\
13,247(20.2)\end{array}$} \\
\hline Total & & & & \\
\hline \multirow[t]{5}{*}{$\mathrm{Age}^{\mathrm{e}}$} & $16-54$ & $26,240(40.1)$ & $7527(28.7)$ & $4709(18.0)$ \\
\hline & $55-64$ & $10,054(15.3)$ & $2698(26.8)$ & $1839(18.3)$ \\
\hline & $65-74$ & $8685(13.3)$ & $2255(26.0)$ & $1749(20.1)$ \\
\hline & $75-84$ & $11,931(18.2)$ & $2765(23.2)$ & $2788(23.4)$ \\
\hline & $\geq 85$ & $8576(13.1)$ & $1927(22.5)$ & $2162(25.2)$ \\
\hline \multirow[t]{2}{*}{ Gender $^{\mathrm{e}}$} & Male & $34,031(52.0)$ & $9329(27.4)$ & $6105(17.9)$ \\
\hline & Female & $31,455(48.0)$ & $7843(24.9)$ & $7142(22.7)$ \\
\hline \multirow[t]{4}{*}{ Number of comorbidities } & 0 & $43,269(66.1)$ & $11,554(26.7)$ & $8007(18.5)$ \\
\hline & 1 & $12,442(19.0)$ & $3168(25.5)$ & $2817(22.6)$ \\
\hline & 2 & $5844(8.9)$ & $1473(25.2)$ & $1433(24.5)$ \\
\hline & $\geq 3$ & $3931(6.0)$ & $977(24.9)$ & $990(25.2)$ \\
\hline \multirow[t]{4}{*}{ Mechanism of injury } & Motor vehicle collision & $14,707(22.4)$ & $4143(28.2)$ & $2244(15.3)$ \\
\hline & Fall & $41,170(62.9)$ & $10,072(24.5)$ & $9202(22.4)$ \\
\hline & Penetrating & $2226(3.4)$ & $774(34.8)$ & $495(22.2)$ \\
\hline & Other & $7383(11.3)$ & $2183(30.0)$ & $1306(17.7)$ \\
\hline \multirow{4}{*}{$\begin{array}{l}\text { Maximum abbreviated } \\
\text { injury scale score }\end{array}$} & $1-2$ & $26,894(41.1)$ & 7428 (27.6) & $5505(20.5)$ \\
\hline & 3 & $28,271(43.2)$ & $7136(25.2)$ & $5681(20.1)$ \\
\hline & 4 & $6787(10.3)$ & $1767(26.0)$ & $1251(18.4)$ \\
\hline & $5-6$ & $3534(5.4)$ & $841(23.8)$ & $810(22.9)$ \\
\hline \multirow{6}{*}{$\begin{array}{l}\text { Body Region, } \\
\text { most severe injury }\end{array}$} & Head & $12,749(19.5)$ & $3333(26.1)$ & $2783(21.8)$ \\
\hline & Thorax & 9096 (13.9) & $2486(27.3)$ & $1663(18.3)$ \\
\hline & Abdomen & $1854(2.8)$ & $528(28.5)$ & $378(20.4)$ \\
\hline & Spine & $6784(10.4)$ & $1687(24.9)$ & $1263(18.6)$ \\
\hline & Upper extremities & $11,274(17.2)$ & $3041(27.0)$ & $2366(21.0)$ \\
\hline & Lower extremities & $23729(36.2)$ & $6097(25.7)$ & $4794(20.2)$ \\
\hline \multirow[t]{3}{*}{ Glasgow coma scale ${ }^{f}$} & $3-8$ & $3358(5.1)$ & $949(28.3)$ & $602(17.9)$ \\
\hline & $9-12$ & $2010(3.1)$ & $512(25.5)$ & $459(22.8)$ \\
\hline & $13-15$ & $60,118(91.8)$ & $15,711(26.1)$ & $12,186(20.3)$ \\
\hline \multirow[t]{2}{*}{ Systolic blood pressure ${ }^{f}$} & Normal $(\geq 90)$ & $64,302(98.2)$ & $16842(26.2)$ & $13,012(20.2)$ \\
\hline & Shock (0-89) & $1184(1.8)$ & $330(27.9)$ & $235(19.9)$ \\
\hline \multirow[t]{2}{*}{ Respiration rate ${ }^{f}$} & Normal (10-29) & $63,869(97.5)$ & $16,732(26.2)$ & $12,934(20.3)$ \\
\hline & Abnormal $(0-10 ; \geq 30)$ & $1617(2.5)$ & $440(27.2)$ & $313(19.4)$ \\
\hline \multirow[t]{2}{*}{ Transfer-in } & No & $44,526(68.0)$ & $10,190(23.0)$ & 9958 (22.4) \\
\hline & Yes & $20,960(32.0)$ & $6982(33.3)$ & 3289 (15.7) \\
\hline \multirow[t]{5}{*}{ Health care payer } & Provincial public & $43,771(66.9)$ & $11,794(26.9)$ & $9210(21.0)$ \\
\hline & Road accidents & $11,282(17.2)$ & 3019 (26.8) & $1954(17.3)$ \\
\hline & Work accidents & $2903(4.4)$ & $868(29.9)$ & 401 (13.8) \\
\hline & Other & $3586(5.5)$ & $679(18.9)$ & $744(20.8)$ \\
\hline & None/Unknown & $3944(6.0)$ & 812 (20.6) & $938(23.8)$ \\
\hline \multirow[t]{3}{*}{ Residential remoteness } & Metropolitan Region ${ }^{a}$ & $21,282(32.5)$ & $2969(14.0)$ & $5975(28.1)$ \\
\hline & Other Regions ${ }^{b}$ & $11,214(17.1)$ & $1807(16.1)$ & 3065 (27.3) \\
\hline & Agglomerations $^{c}$ & $11,824(18.1)$ & $2654(22.5)$ & $3328(28.2)$ \\
\hline
\end{tabular}


Table 1 Description of the study population according to the highest levels of material and social deprivation (Continued)

\begin{tabular}{lllll}
\hline \multirow{2}{*}{ Discharge destination } & Small towns \& rural areas ${ }^{\mathrm{d}}$ & $21,166(32.3)$ & $9742(46.0)$ & $879(4.2)$ \\
& Home & $38,276(58.5)$ & $10,230(26.7)$ & $6960(18.2)$ \\
& Long stay & $4264(6.5)$ & $806(18.9)$ & $1146(26.9)$ \\
& Rehab & $6145(9.4)$ & $1313(21.4)$ & $1500(24.4)$ \\
& Acute care & $5531(8.5)$ & $1842(33.3)$ & $1080(19.5)$ \\
& Other & $11,270(17.1)$ & $2981(26.5)$ & $2493(22.6)$ \\
\hline
\end{tabular}

${ }^{a}$ population size: $>1,000,000$

${ }^{b}$ population size: $100,000-1,000,000$

cpopulation size: $10,000-100,000$

dpopulation size: $<10,000$

e Deprivation index is standardized for age and sex

fOn arrival

We did not adjust for health care payer, residential remoteness, or discharge destination as these factors are considered to be mediators in the SES-LOS association and/or strong proxies for SES [30]. Based on evidence in the literature, we hypothesized, à priori, that the influence of social/material deprivation on LOS would differ for young and geriatric patients [31]. Analyses were therefore performed for the whole study sample and according to age group ( $<65, \geq 65$ years old). Note that we chose a simple linear model over more complex models (e.g., log-linear or gamma models) because arithmetic means have been shown to be an unbiased and efficient estimator of the mean for skewed data given large sample sizes [32, 33], mean differences are more intuitive than geometric mean ratios and sensitivity analysis showed that using more complex models did not change study conclusions. LOS $>120$ days were truncated at 120 days [34].

The GCS, RR, and SBP were missing for $57 \%, 33 \%$ and $12 \%$ of data observations, respectively. As previously described, these data were mostly missing in patients with minor extracranial injury [35]. Missing data were simulated using multiple imputation. The Markov Chain Monte Carlo method was used with a non-informative prior and a single chain to generate five imputes for each missing data value $[35,36]$. The imputation model included all independent and dependant variables used in the analyses models.

\section{Sensitivity analyses}

We used sensitivity analyses to evaluate the robustness of study results to the exclusion of deaths, GCS/SBP/RR simulated by multiple imputation and additional hospital days due to transfer. Risk-adjusted mean differences in LOS for SES quintiles in the original analysis were thus compared to those generated by models with i) deaths included but attributed the maximum observed LOS (120 days) [37], ii) observations with missing GCS/SBP/RR excluded, and iii) index LOS replaced with total LOS for all consecutive hospital admissions for the same injury. For the latter, we used trauma registry data linked to hospital administrative discharge data, as described elsewhere [30].

All analyses were performed using SAS software (Version 9.4 of the SAS System for Windows, Copyright (C), SAS Institute Inc., Cary, NC, USA) and statistical tests were two-sided with statistical significance set at $5 \%$. Ethics approval for this study was obtained from the Comité d'éthique de la recherche avec des êtres humains de l'Université Laval and the Comité d'éthique du Centre Hospitalier Universitaire de Québec.

\section{Results}

Between April 1, 2007 and February 28, 2012, 72,009 patients were eligible for the study. A deprivation index couldn't be assigned to 2686 patients (3.7 \%) due to a missing or invalid postal code and to 3837 patients (5.3\%) because no SES information was available for their residential zone (i.e., patients living in a high density long term care/ institutional facilities or in a rural community with very low density population) [19]. The final study population therefore comprised 65,486 patients.

Over $40 \%$ of the study population was aged $\geq 65$ years, over one half were male and one fifth of patients were admitted for major trauma (Injury Severity Score $>15$ ). Social deprivation increased with age and was more prevalent in patients with multiple comorbidities whereas material deprivation was lower for elderly patients (Table 1). Material deprivation was higher in males than in females, but we observed the opposite for social deprivation. However, the associations between age/gender and SES indices are difficult to interpret as the latter are standardized for age and gender. Material deprivation was more prevalent in patients with penetrating injuries but decreased with increasing injury severity. Social deprivation increased with increasing injury severity but was less prevalent in patients covered by work accident insurance than those covered by other health care payers. Patients residing in metropolitan regions suffered from 
higher social deprivation but lower material deprivation than patients residing in rural areas.

Mean LOS for the whole study population was 13.5 days. After risk adjustment, patients in the highest quintile of material deprivation had an LOS 0.5 days longer than those in the lowest quintile (Fig. 1, Table 2). However, LOS did not increase over the first four quintiles of material deprivation. Mean LOS increased with every quintile of social deprivation and was 1.4 days longer for patients in the highest quintile of social deprivation compared to those in the lowest quintile. The increase in LOS was even greater for patients in the highest quintiles of material and social deprivation who had a hospital stay on average 2.6 days longer than patients in the lowest quintiles. When analyses were stratified for age, increases in LOS associated with social deprivation and social-material deprivation were greater for elderly patients than their younger counterparts (Table 2). However, unlike patients $<65$, elderly patients suffering from high material deprivation did not have a longer LOS.

\section{Sensitivity analyses}

Modelling deaths $(n=3012,4.6 \%)$ by attributing an LOS of 120 days led to a slightly smaller difference in LOS for patients in the highest quintile of material, social and material-social deprivation (mean adjusted difference $=0.32,1.21$, and 2.38 days, respectively). Excluding observations with missing physiological data led to a slightly larger difference in LOS for patients in the highest quintile of material deprivation (mean adjusted increase $=0.64$ ) but a slightly smaller difference for patients in the highest quintile of social and material-social deprivation (mean adjusted difference $=1.08$ and 2.31 days, respectively). Overall, $6.7 \%$ of patients had more than one consecutive hospital stay related to their injury. Mean total LOS was 1.2 days longer than mean index LOS (14.6 days). The SES-LOS association remained unchanged when total LOS was modelled over index LOS.

\section{Discussion}

In this multicenter cohort study in an integrated and universal access trauma system, patients admitted for injury in the highest quintiles of social and material deprivation had an acute care stay on average 2.6 days or $24 \%$ longer than patients in the lowest quintiles. The observed difference in LOS was more pronounced for social deprivation (1.4 days on average) than for material deprivation ( 0.5 days on average) and was even greater for patients suffering both material and social deprivation.

The association between SES and hospital LOS has been inconsistently documented in the literature. Increases in LOS for increasing material deprivation have been reported for general admissions in inclusive healthcare systems [7] but not in for-profit systems [38]. Increases have also been observed for US stroke admissions [8] and admissions for patients $<65$ years of age with a primary diagnosis of pneumonia in Canada [10] but not for patients admitted for traumatic brain injury in the US [39] or geriatric patients admitted for pneumonia [9]. However, all of these studies were based on only one dimension of material deprivation, median neighborhood income. Few studies have evaluated the association between social deprivation and LOS but one study in elderly pneumonia admissions observed a longer LOS for patients living alone [9]. We identified four studies that used multifactorial composite indices of social/material deprivation to evaluate the association between SES and hospital LOS. Longer LOS was observed for high deprivation categories in coronary artery

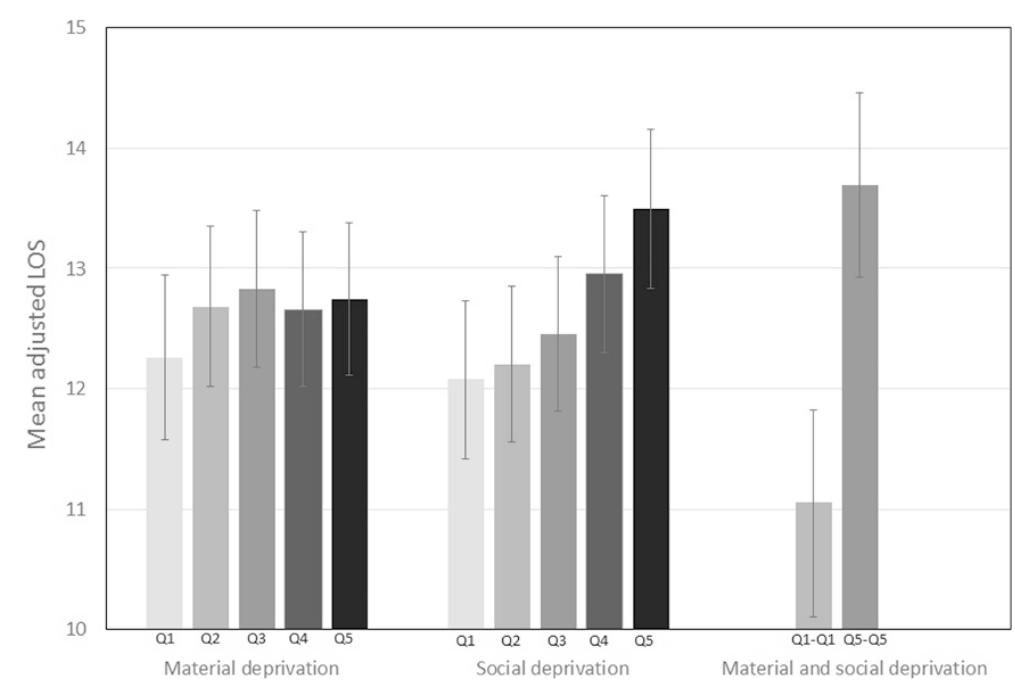

Fig. 1 Adjusted mean acute care length of stay according to material and social deprivation 
Table 2 Adjusted mean differences and $95 \%$ confidence intervals (CI) in hospital length of stay (LOS) according to socio-economic deprivation by age

\begin{tabular}{|c|c|c|c|c|}
\hline \multirow[t]{2}{*}{ Socio-economic status } & \multirow[t]{2}{*}{$N(\%)$} & \multicolumn{3}{|c|}{ Adjusted $^{a}$ difference in mean LOS (95 \% Cl) } \\
\hline & & All patients & $<65$ years & $\geq 65$ years \\
\hline \multicolumn{5}{|l|}{ Material deprivation } \\
\hline Q1 & $8639(13.2)$ & 1.00 & 1.00 & 1.00 \\
\hline Q2 & $11,229(17.2)$ & $0.43(0.04-0.82)$ & $0.36(-0.05-0.77)$ & $0.35(-0.35-1.05)$ \\
\hline Q3 & $13,439(20.5)$ & $0.57(0.20-0.95)$ & $0.57(0.17-0.97)$ & $0.33(-0.35-1.02)$ \\
\hline Q4 & $15,007(22.9)$ & $0.41(0.03-0.78)$ & $0.37(-0.02-0.77)$ & $0.23(-0.45-0.90)$ \\
\hline Q5 & $17,172(26.2)$ & $0.49(0.12-0.87)$ & $0.70(0.32-1.09)$ & $-0.01(-0.71-0.69)$ \\
\hline Trend p-value & & 0.048 & 0.006 & 0.7 \\
\hline \multicolumn{5}{|l|}{ Social deprivation } \\
\hline Q1 & $11,551(17.6)$ & 1.00 & 1.00 & 1.00 \\
\hline Q2 & $13,108(20.0)$ & $0.13(-0.22-0.47)$ & $0.13(-0.21-0.48)$ & $0.15(-0.52-0.83)$ \\
\hline Q3 & $13,932(21.3)$ & $0.38(0.03-0.72)$ & $0.46(0.12-0.81)$ & $0.38(-0.29-1.04)$ \\
\hline Q4 & $13,648(20.8)$ & $0.87(0.53-1.22)$ & $0.69(0.33-1.04)$ & $1.08(0.43-1.73)$ \\
\hline Q5 & $13,247(20.2)$ & $1.42(1.06-1.77)$ & $1.22(0.86-1.59)$ & $1.70(1.04-2.36)$ \\
\hline Trend p-value & & $<0.0001$ & $<0.0001$ & $<0.0001$ \\
\hline \multicolumn{5}{|c|}{ Material and social deprivation } \\
\hline Q1-Q1 & $1379(2.1)$ & 1.00 & 1.00 & 1.00 \\
\hline Q5-Q5 & $3535(5.4)$ & $2.64(1.77-3.50)$ & $2.27(1.41-3.13)$ & $3.22(1.54-4.90)$ \\
\hline$P$-value & & $<0.0001$ & $<0.0001$ & $<0.0001$ \\
\hline
\end{tabular}

LOS length of stay, $Q$ quintile

${ }^{a}$ Adjusted for age, gender, number of comorbidities, mechanism of injury, Maximum Abbreviated Injury Scale score, body region of the most severe injury,

Glasgow Coma Scale score, systolic blood pressure, respiratory rate, and transfer status

bypass [40], chronic obstructive pulmonary disease [41] and psychiatric [11] admissions but not for stroke patients [42]. However, these studies did not report results separately for social and material deprivation and no stratification was conducted for age.

Further analyses are needed to evaluate whether prolonged hospital stays among patients suffering high material and in particular, social deprivation are inappropriate and to identify factors that may explain the observed difference. However, research suggests that up to $80 \%$ of unnecessary hospital days are due to delays accessing government-funded long-term care facilities or community aid [10, 43, 44]. Increased LOS in patients with low SES would thus be consistent with lack of access to natural caregivers (social deprivation) $[10,45,46]$ and lack of material resources to pay for private post-discharge care (material deprivation) [7]. The weaker association for material deprivation observed in this study may be due to the presence of a universal healthcare system and a strong social safety net in Canada. The lack of association between material deprivation and LOS in elderly patients has been observed elsewhere [9, 38] and may be due to the greater presence of community care and long-term care facilities for elderly patients than their younger counterparts.

\section{Strengths and limitations}

This study population is representative of moderate to major trauma admissions in the province (population based) because it includes admissions to all trauma centers (level I to level IV) in a fully integrated system. Previous research has shown that over $90 \%$ of patients hospitalized for major trauma in the province are treated within the trauma system [47]. In addition, the trauma registry used in this study is audited periodically to ensure data quality and audit results suggest high data accuracy (only 76 errors in 65 data fields $\times 80$ patient files; data not published). Furthermore, our study used a comprehensive measure of SES based on six indicators of social and material deprivation.

However, this study does have limitations which should be considered in the interpretation of results. First, SES was defined using an ecological measure 
instead of an individual measure, which may have led to an underestimation of the SES-LOS association [31]. However, one advantage of ecological measures is that they take account of the living environment and neighborhood influences [48]. Second, we excluded $9 \%$ of patients due to missing information on SES. Patients with missing SES had a longer mean LOS (14.8 days) than those included in the study (13.5 days). SES was mainly missing in low-density rural areas and areas where more than $15 \%$ of the total population live in institutions or collective households [31]. Considering these patients are likely to have higher levels of material and social deprivation and worse outcomes than those included, SES-LOS associations may again have been underestimated. Third, approximately $10 \%$ of major trauma cases are treated in non-designated centers in the province and so were not included in this study [47]. However, we have no reason to believe that the association between SES and LOS would not be observed in trauma patients treated outside the system. Fourth, previous research suggests that low SES is associated with an increased risk of unplanned readmission [12, 14, 49]. We anticipate that not accounting for these additional acute care days may have led to an underestimation of the SES-LOS association in our study. Fifth, poor data quality, a common problem in retrospectively-collected data, may have led to residual confounding due to unmeasured severity. However, misclassification of injury severity would only explain observed differences in LOS if injury severity is more frequently underestimated in patients with high social deprivation, which we consider unlikely. Finally, results may be subject to survival bias because deaths were excluded from analysis. Indeed, if low SES is associated with a higher probability of death following admission for injury, the exclusion of fatalities may have led us to underestimate the association between SES and LOS. However, an analysis with deaths included and attributed an arbitrarily long LOS led to similar results.

\section{Potential policy implications}

The results of this study may have important implications for improving resource use and outcomes for patients admitted following injury that suffer from material and social deprivation. Indeed, given the volume of injury hospitalizations in Canada (205,000 per year) [17] and an average cost per acute care bed of CAN\$ 360.95 [6], reducing mean LOS to that observed in the lowest quintiles of material and social deprivation would lead to savings of approximately 513,282 (13\% of 185,000 bed days) or CAN\$ 185 million per year in Canada. In addition, given the negative consequences of prolonged LOS in terms of adverse events including hospital-acquired infections and functional decline [3-5], interventions designed to reduce the influence of social disparities on LOS may have the potential to improve patient morbidity and mortality. These interventions could include comprehensive patient risk assessment, early discharge planning and patient education. These interventions, along with effective communication and cooperation between health and social workers as well as hospital and community care systems, have been shown to decrease unnecessary acute care days [6]. Results also suggest that SES should be taken into account in hospital resource allocations to avoid unfairly penalizing hospitals in areas of high socioeconomic deprivation [7].

\section{Conclusion}

Patients admitted for injury suffering from material and particularly social deprivation may have longer mean LOS than their counterparts in a universal healthcare setting. Further research is needed to identify factors contributing to possibly unnecessary acute care days in these patients. Results suggest that consideration of SES in discharge planning and community care attribution may lead to reductions in LOS, which would in turn improve resource use and outcomes for injury admissions.

\section{Abbreviations}

LOS: Length of stay; SES: Socio-economic status; MAIS: Maximum abbreviated injury scale score; GCS: Glasgow coma scale score; SBP: Systolic blood pressure; RR: Respiratory rate.

\section{Competing interests}

The authors declare that they have no competing interests.

\section{Authors' contributions}

LM contributed substantially to the conception and design of the study, data acquisition, interpretation of data, revised the manuscript critically for important intellectual content, and drafted the manuscript. BC contributed substantially to the conception and design of the study, interpretation of data, revised the manuscript critically for important intellectual content, and gave final approval of the version to be published. BLBK contributed substantially to the interpretation of data, revised the manuscript critically for important intellectual content, and gave final approval of the version to be published. HTS contributed substantially to the interpretation of data, revised the manuscript critically for important intellectual content, and gave final approval of the version to be published. AFT contributed substantially to the interpretation of data, revised the manuscript critically for important intellectual content, and gave final approval of the version to be published. FL contributed substantially to the interpretation of data, revised the manuscript critically for important intellectual content, and gave final approval of the version to be published. $J$ contributed substantially to data acquisition, the interpretation of data, revised the manuscript critically for important intellectual content, and gave final approval of the version to be published. GB contributed substantially to data acquisition, the interpretation of data, revised the manuscript critically for important intellectual content, and gave final approval of the version to be published. All authors read and approved the final manuscript.

\section{Acknowledgements}

This work was supported by the Canadian Institutes of Health Research (CIHR; grant \#110996); and the Fonds de Recherche du Québec-Santé (FRQS; grant \#24444) funded this study. L Moore, AF Turgeon and HT Stelfox are recipients of a CIHR new investigator award; F Lauzier is recipient of a FRQ-S research salary support award. 


\section{Author details}

${ }^{1}$ Department of social and preventive medicine, Laval University, Quebec, QC, Canada. ${ }^{2}$ Population Health and Optimal Health Practices Research Unit, Trauma - Emergency - Critical Care Medicine, Centre de Recherche du Centre Hospitalier Universitaire de Québec (CHU de Québec - Hôpital de I'Enfant-Jésus), Laval University, Québec, QC, Canada. ${ }^{3}$ Department of Critical Care Medicine, Medicine and Community Health Sciences, Institute for Public Health, University of Calgary, Calgary, AB, Canada. ${ }^{4}$ Department of Anesthesiology and Critical Care Medicine, Division of Critical Care Medicine, Laval University, Québec, QC, Canada. ${ }^{5}$ Department of Medicine, Laval University, Québec, QC, Canada. ${ }^{6}$ Department of Surgery, Laval University, Québec, QC, Canada. 'Institut National d'Excellence en Santé et en Services Sociaux, Montréal, Qc, Canada.

\section{Received: 28 October 2014 Accepted: 14 July 2015} Published online: 25 July 2015

\section{References}

1. Raymond G, Pampalon R. Indice de défavorisation matérielle et sociale : son application au secteur de la santé et du bien-être. Santé, Société et Solidarité. 2003;191-208.

2. McDonagh MS, Smith DH, Goddard M. Measuring appropriate use of acute beds. A systematic review of methods and results. Health Policy. 2000;53(3):157-84

3. Caminiti C, Meschi T, Braglia L, Diodati F, lezzi E, Marcomini B, et al. Reducing unnecessary hospital days to improve quality of care through physician accountability: a cluster randomised trial. BMC Health Serv Res. 2013;13:14.

4. Covinsky KE, Palmer RM, Fortinsky RH, Counsell SR, Stewart AL, Kresevic D, et al. Loss of independence in activities of daily living in older adults hospitalized with medical illnesses: increased vulnerability with age. J Am Geriatr Soc. 2003;51(4):451-8

5. Shojania KG, Duncan BW, McDonald KM, Wachter RM. Safe but sound: patient safety meets evidence-based medicine. JAMA. 2002;288(4):508-13.

6. World Health Organization: Estimates of Unit Costs for Patient Services for Canada. Available at: http://www.who.int/choice/country/can/cost/en/ index.html. Accessed April 26, 2014

7. Perelman J, Closon MC. Impact of socioeconomic factors on in-patient length of stay and their consequences in per case hospital payment systems. J Health Serv Res Policy. 2011;16(4):197-202.

8. Hanchate AD, Schwamm LH, Huang W, Hylek EM. Comparison of ischemic stroke outcomes and patient and hospital characteristics by race/ethnicity and socioeconomic status. Stroke; J Cerebral Circ. 2013:44(2):469-76.

9. Izquierdo C, Oviedo M, Ruiz L, Sintes X, Vera I, Nebot M, et al. Influence of socioeconomic status on community-acquired pneumonia outcomes in elderly patients requiring hospitalization: a multicenter observational study. BMC Public Health. 2010;10:421.

10. McGregor MJ, Reid RJ, Schulzer M, Fitzgerald JM, Levy AR, Cox MB. Socioeconomic status and hospital utilization among younger adult pneumonia admissions at a Canadian hospital. BMC Health Serv Res. 2006;6:152.

11. Abas MA, Vanderpyl J, Robinson E, Le Prou T, Crampton P. Socio-economic deprivation and duration of hospital stay in severe mental disorder. Br J Psychiatry J Ment Sci. 2006;188:581-2.

12. Calvillo-King L, Arnold D, Eubank K, Lo M, Yunyongying P, Stieglitz H, et al. Impact of social factors on risk of readmission or mortality in pneumonia and heart failure: systematic review. J Gen Intern Med. 2013;28(2):269-82.

13. Webb S, Yaguez L, Langdon PE. Factors associated with multiple readmission to a psychiatric hospital. J Ment Health. 2007;16(5):647-61.

14. Roberts ME, Lowndes L, Milne DG, Wong CA. Socioeconomic deprivation, readmissions, mortality and acute exacerbations of bronchiectasis. Intern Med J. 2012;42(6):e129-136

15. Bernheim SM, Spertus JA, Reid KJ, Bradley EH, Desai RA, Peterson ED, et al. Socioeconomic disparities in outcomes after acute myocardial infarction. Am Heart J. 2007:153(2):313-9.

16. Moore L, Turgeon AF, Sirois MJ, Murat V, Lavoie A. Influence of socioeconomic status on trauma center performance evaluations in a Canadian trauma system. J Am Coll Surg. 2011;213(3):402-9.

17. Injury Hospitalizations and Socio-Economic Status [https://secure.cihi.ca/ free_products/Injury_aib_vE4CCF_v3_en.pdf]
18. Tiao J, Moore L, Boutin A, Turgeon AF. Establishing consensus on the definition of an isolated hip fracture for trauma system performance: A systematic review. JETS. 2014;7(3):209-14.

19. Pampalon R, Hamel D, Gamache P, Raymond G. A deprivation index for health planning in Canada. Chronic Dis Can. 2009;29(4):178-91.

20. Pampalon R, Hamel D, Gamache P, Philibert MD, Raymond G, Simpson A An area-based material and social deprivation index for public health in Quebec and Canada. Can J Public Health. 2012;103(8 Suppl 2):S17-22.

21. Townsend P. Deprivation and ill health. Nursing. 1991;4(43):11-5.

22. Blais C, Hamel D, Rinfret S. Impact of socioeconomic deprivation and area of residence on access to coronary revascularization and mortality after a first acute myocardial infarction in Quebec. Can J Cardiol. 2012;28(2):169-77.

23. Lowcock EC, Rosella LC, Foisy J, McGeer A, Crowcroft N. The social determinants of health and pandemic H1N1 2009 influenza severity. Am J Public Health. 2012;102(8):e51-58.

24. Morassaei S, Breslin FC, Ibrahim SA, Smith PM, Mustard CA, Amick 3rd BC, et al. Geographic variation in work injuries: a multilevel analysis of individual-leve data and area-level factors within Canada. Ann Epidemiol. 2013;23(5):260-6.

25. Remes O, Smith LM, Alvarado-Llano BE, Colley L, Levesque LE. Individual- and regional-level determinants of human papillomavirus (HPV) vaccine refusal: the Ontario Grade 8 HPV vaccine cohort study. BMC Public Health. 2014;14:1047.

26. Terashima M, Rainham DG, Levy AR. A small-area analysis of inequalities in chronic disease prevalence across urban and non-urban communities in the Province of Nova Scotia, Canada, 2007-2011. BMJ Open. 2014;4(5), e004459.

27. Charlson ME, Pompei $P$, Ales KL, MacKenzie CR. A new method of classifying prognostic comorbidity in longitudinal studies: development and validation. J Chronic Dis. 1987:40(5):373-83.

28. AAAM. Abbreviated Injury Scale (AIS) 1990. Illinois: AAAM Publications; 1990.

29. Teasdale $G$, Jennett B. Assessment of coma and impaired consciousness. A practical scale. Lancet. 1974;2(7872):81-4.

30. Moore L, Stelfox HT, Turgeon AF, Nathens AB, Lavoie A, Bourgeois G, et al. Derivation and validation of a quality indicator for 30-day unplanned hospital readmission to evaluate trauma care. J Trauma Acute Care Surg. 2014;76(5):1310-6.

31. Aging, deprivation, and health: A "triple jeopardy" faced by the older population [http://hdl.handle.net/1974/8341]

32. Briggs A, Nixon R, Dixon S, Thompson S. Parametric modelling of cost data: some simulation evidence. Health Econ. 2005;14(4):421-8.

33. Manning WG, Mullahy J. Estimating log models: to transform or not to transform? J Health Econ. 2001;20(4):461-94.

34. Ruffieux C, Paccaud F, Marazzi A. Comparing rules for truncating hospital length of stay. Casemix Quaterly. 2000;2(1):1-10.

35. Moore L, Lavoie A, LeSage N, Liberman M, Sampalis JS, Bergeron E, et al. Multiple imputation of the Glasgow coma score. J Trauma. 2005;59(3):698-704.

36. Little RJ, Rubin DB. Statistical analysis with missing data, vol. 539, 2nd edn. New York, NY: Wiley; 2002.

37. Brock GN, Barnes C, Ramirez JA, Myers J. How to handle mortality when investigating length of hospital stay and time to clinical stability. BMC Med Res Methodol. 2011:11:144.

38. Weingarten JP, Clay JC, Heckert DA. Impact of socioeconomic status on health care utilization: factors influencing length of stay. J Health Hum Serv Adm. 1997;19(4):384-409.

39. Heffernan DS, Vera RM, Monaghan SF, Thakkar RK, Kozloff MS, Connolly MD, et al. Impact of socioethnic factors on outcomes following traumatic brain injury. J Trauma. 2011;70(3):527-34.

40. Taylor FC, Ascione R, Rees K, Narayan P, Angelini GD. Socioeconomic deprivation is a predictor of poor postoperative cardiovascular outcomes in patients undergoing coronary artery bypass grafting. Heart. 2003;89(9):1062-6.

41. Agboado G, Peters J, Donkin L. Factors influencing the length of hospital stay among patients resident in Blackpool admitted with COPD: a cross-sectional study. BMJ Open. 2012;2(5):e000869.

42. Wong KY, Wong SY, Fraser HW, Ersoy Y, Ogston S, Wolfson D, et al. Effect of social deprivation on mortality and the duration of hospital stay after a stroke. Cerebrovascular Dis. 2006:22(4):251-7.

43. Welch WP, Dubay LC. The impact of administratively necessary days on hospital costs. Med Care. 1989;27(12):1117-32.

44. Majeed MU, Williams DT, Pollock R, Amir F, Liam M, Foong KS, et al. Delay in discharge and its impact on unnecessary hospital bed occupancy. BMC Health Serv Res. 2012;12:410. 
45. Wong AW, Gan WQ, Burns J, Sin DD, van Eeden SF. Acute exacerbation of chronic obstructive pulmonary disease: influence of social factors in determining length of hospital stay and readmission rates. Can Respir J : J Can Thoracic Soc. 2008;15(7):361-4.

46. Ashton CM, Kuykendall DH, Johnson ML, Wray NP, Wu L. The association between the quality of inpatient care and early readmission. Ann Intern Med. 1995;122(6):415-21.

47. Kuimi BL, Moore L, Cisse B, Gagné M, Lavoie A, Bourgeois G, et al. Access to a Canadian provincial integrated trauma system: a population-based cohort study. Injury. 2015;46(4):595-601.

48. Subramanian SV, Chen JT, Rehkopf DH, Waterman PD, Krieger N. Comparing individual- and area-based socioeconomic measures for the surveillance of health disparities: A multilevel analysis of Massachusetts births, 1989-1991. Am J Epidemiol. 2006;164(9):823-34

49. Bernheim SM, Spertus JA, Reid KJ, Bradley EH, Desai RA, Peterson ED, et al. Socioeconomic disparities in outcomes after acute myocardial infarction. Am Heart J. 2007;153(2):313-9.

\section{Submit your next manuscript to BioMed Central and take full advantage of:}

- Convenient online submission

- Thorough peer review

- No space constraints or color figure charges

- Immediate publication on acceptance

- Inclusion in PubMed, CAS, Scopus and Google Scholar

- Research which is freely available for redistribution 